\title{
Entrevista: António Ole, pintor, escultor e cineasta Angolano
}

Por Carlos Alberto Alves'

António Ole nasceu em Luanda, Angola, em 1951. Estudou Cultura AfroAmericana na Universidade de Califórnia e é diplomado pelo Center for Advance Film Studies do American Institute. Trabalhou na televisão de Angola como realizador de programas. Realizou exposições em Angola, África do Sul, Brasil, Cuba, Espanha, EUA, Escócia, Portugal, Suécia e Zimbabwé.

Nesta entrevista realizada em Lisboa no mês de maio de 1995 António Ole confessa-nos a sua perceção de enriquecimento da obra de arte que fará o público, quer aquele que permanece, quer aquele que se renova. Daí a sua contemporaneidade. Ele mantém o cordão umbilical ligado à sua terra de origem em relação à qual no passado não hesitou em denunciar numa atitude de desafio através da grande carga irônica da sociedade colonial de então.

António Ole, artista plurifacetado, recorda ter como principal objetivo uma criação plástica irônica a descodificar em qualquer parte do mundo onde a cultura africana nos seus variados aspectos terá de entrar no uso corrente. Com António Ole me congratulo pelo interesse revelado no início do século XX por alguns artistas europeus como: Matisse, Derain, Picasso e tantos outros pela arte africana.

\section{Gostaria de saber quando começou a pintar?}

Comecei a pintar há cerca de 25 anos, o que corresponde, sensivelmente, ao período em que estudava no Liceu. Alguns professores viam em mim certas potencialidades. Estimularam-me, então, para que eu participasse em algumas exposições, em Luanda - organizadas pela Câmara Municipal - nas festas da cidade. São dessa época as minhas primeiras exposições coletivas.

\section{Houve algum pintor que influenciou a sua carreira?}

\footnotetext{
${ }^{1}$ Colaborador do CIID - Centro de Investigação Identidade (s) e Diversidade (s) - Instituto Politécnico de Leiria (Portugal).
} 
Inicialmente, quando comecei a dar os primeiros passos, estava influenciado pela pintura de Picasso e de Braque.

As obras que fez, para além do valor que possuem, devem ser entendidas, como ato de dignidade e crítica, ou apenas como manifestação intrínseca daquilo que têm?

Elas devem ser entendidas como um projeto artístico do qual o espectador possa tirar as suas próprias conclusões. Eu não tenho uma "receita", tenho uma proposta artística com uma leitura aberta para todos. Acho que nessa relação entre produtor e espectador existe um vasto leque de leituras que podem enriquecer a obra de arte.

Não tenho uma "receita" própria. O meu trabalho assenta nesse aspecto dito tradicional. Assim, pretendo mostrar ou ter uma visão contemporânea.

Com o início, de certa forma, do trabalho no cinema, ligado a assuntos culturais, isto é, registo e cooperação de coisas que eram do domínio da tradição oral, lentamente, nesse projeto, acabei por acumular cargos e conhecimentos que me permitiram retornar à pintura.

A minha pintura dos anos setenta faz um "mergulho" na tradição angolana, embora eu não estivesse interessado em repetir o que faziam os Tchokwes ${ }^{2}$. Tomei este ponto de partida para fazer as minhas próprias produções, usando exatamente a carga desse registo simbólico da cultura tradicional e aplicando-a à pintura. Entretanto, isto acaba por ser um trabalho simultâneo entre filmes e pinturas.

Atualmente, o cinema acabou por se distanciar, porque as estruturas estão completamente descativadas. Achei, numa certa época, que devia concentrar-me na arte, que continuo a desenvolver até ao momento.

Aguardo bons tempos para poder voltar ao cinema, porque tenho projetos que se arrastam há algum tempo. Não tenho possibilidade de poder rever esses filmes no país profundo. Por isso, neste momento, a minha prática em relação ao cinema tem sido limitada.

\section{Teve problemas com o Governo de Angola?}

\footnotetext{
2 Povo conhecido pelo seu talento artístico.
} 
Não. Nunca tive problemas com o Governo. Apenas censurou o filme "O Ritmo dos Ngola Ritmos"3 por uma das pessoas centrais deste grupo ser o falecido liderante maestro Liceu Vieira Dias (Carlos Aniceto Vieira Dias), uma pessoa da oposição.

Leonel Moura, no catálogo de apresentação da sua exposição “Terra parda, terra mista", escreveu: «África é seguramente o elo mais forte e também o mais desprezado. Aquele que, no domínio cultural, mais tem sofrido de uma indesculpável falta de atenção e solidariedade. Aquele, afinal com o qual nos poderíamos sentir mais idênticos e melhor nos ajudar a ganhar a diferença na Europa dos Mercados e da normalização».

$\mathrm{O}$ autor desse texto referia-se à minha exposição realizada em Lisboa, no atelier “Troufa Real”. Ele fazia menção a Portugal. O facto de ser um país com cinco séculos de encontro com países como Angola, muitas vezes, esquece as manifestações atuais da arte que se produz. Há uma grande falta de atenção. Acho que Portugal tem alguma responsabilidade neste aspeto, porque há expressões multiculturais que foram forjadas no encontro de culturas.

Por outro lado, a nível internacional, nota-se o contrário: um grande interesse por estas manifestações da dita "arte periférica", arte produzida no "terceiro mundo". Neste momento, um pouco por toda a parte, seja na Inglaterra, nos EUA ou na França há uma série de projetos cujo interesse é provocado pela saturação do próprio esquema de mercado. As pessoas interessadas buscam da mesma forma que os artistas, no princípio do século, se interessaram pela produção de arte feita em África. Agora, esse interesse tem vindo a aumentar. Por exemplo, vi em Nova Iorque, a uns dez anos, uma exposição que consistia em mostrar todas as peças que tinham influenciado toda a geração de artistas europeus. Recentemente, houve uma exposição intitulada: "Le magicien de la terre", que mostrou pintores vindos de várias partes do mundo. Isto parece-me bom. Oxalá não haja intenções neocolonizadoras nesse projeto. Preocupa-me muito. Atenção: acontece que as sociedades capitalistas avançadas têm tendência hegemônica sobre a produção periférica. Por isso, é preciso muita atenção.

\footnotetext{
${ }^{3}$ Realizado em 1978 para homenagear Liceu Vieira Dias e seus companheiros (Manuel dos Passos, Domingos Van Dúnem, Mário de Araújo, Lurdes Van Dúnem, Belita Palma, José Maria, Amadeu Amorim, Fontinhas, Xodó, Cordeiro, Jejé, entre outros) que reinterpretaram a música angolana dos anos quarenta e cinquenta do século XX.
} 


\section{Verificámos nas suas obras uma faceta crítica e irónica. Faz parte da sua filosofia}

artística ou é apenas para ilustrar sentimentos que estão presentes na sociedade que o rodeia?

Nesse momento, a arte interessa-me pela capacidade de provocar o espectador. Por isso, deve ser irónica, porque uma arte passiva não joga com o espectador, não lhe "pisca o olho". Talvez aí possa haver uma leitura nesse sentido, mas digamos que não é o leitmotiv, são efeitos de percurso.

\section{A passagem pela Universidade da Califórnia, onde estudou Cultura Afro-} Americana terá marcado o seu percurso?

Naturalmente. Fui aos EUA para engrandecer os meus conhecimentos em relação ao cinema e a vida. Completei lá trinta anos. Foi uma época muito importante na minha vida porque tive a oportunidade de desenvolver os meus conhecimentos a nível do cinema e de ver exposições de grande nível internacional e de qualidade. Sem querer, acaba por se repercutir no meu trabalho.

Há uma fase na minha pintura, feita nos EUA, muito apelativa, com grande recurso a cor. Julgo que serão os sinais mais evidentes, embora mantendo sempre o "cordão umbilical" com os sinais e a pesquisa que tinha iniciado em Angola, em meados dos anos setenta.

Nos seus trabalhos, procura, de preferência, traduzir a significação eterna, e disso extrair a essência e captar a vida. Não faz “arte pela arte”, com alguma finalidade?

Como the disse ao expor trabalhos de carácter multifacético, evidentemente, não tenho nenhuma "receita" nem uma mensagem específica. São fruto da minha própria reflexão sobre as coisas que me rodeiam e onde vivo. Sou um artista que, não fazendo arte de intervenção, me sinto permeável nas coisas que fazem parte do meu "aquário", com grande e imenso caudal de informações: umas diárias e outras que ficam condensadas na memória. É a esse "aquário" que vou buscar os elementos importante e decisivos para a criação das obras de arte. Não tenho mensagem específica. Pretendo, isto sim, fazer reflexões que sejam justas e, preferencialmente, com alguma precisão em relação àquilo que me rodeia. Eu não faço arte realista. Cada um tem a liberdade de fazer a sua leitura, não me importo. 


\section{O que tem a dizer quanto a produção artística dos países de língua portuguesa em geral?}

Conheço um bocado Moçambique e alguma produção. Dos outros países não tenho informação. Infelizmente, o que se vê é pouco para ter uma opinião geral. Parece-me também que neste espaço amplo de expressão portuguesa há poucos encontros, sendo estes esporádicos e muito vagos.

A produção contemporânea africana defronta-se com alguns clichês que foram desenvolvidos por outros pintores e artistas africanos: para ser um artista africano tem que se ter alguns "condimentos" de carácter étnico religioso. Eu sou contra isso, porque o meu ponto de partida é outro. Serão de fato, esses elementos de carácter tradicional que darão outra tonalidade, mas sinto-me com liberdade suficiente para tirar as minhas ilações, a fim de que o discurso de um pintor africano contemporâneo, como eu, seja entendido em África, na Cochinchina, na Europa e assim por diante. Não quero reduzir o meu trabalho a uma "cozinha artística" que limita o vigor e a liberdade de expressão.

Muitas vezes, parece-me que há grandes equívocos na arte contemporânea que se produz em África porque as pessoas continuam a seguir certos tipos de clichês que são muito bons para os turistas que vão comprar artesanato. Estou completamente distanciado deste tipo de produção.

\section{Que materiais e técnicas usa nos seus trabalhos?}

Preciso, constantemente, de todos os materiais tradicionais: fibras e coisas que apanho no chão. Basta ver toda a escultória, e os objetos "fetiche" que são uma profusão imensa de materiais de toda a ordem. Associa-se um pouco esses materiais, que são de uma tradição europeia académica, e de outra que vem diretamente da minha pesquisa do terreno.

\section{Neste momento em Angola os artistas são livres?}

Não há nada que impeça os artistas de dizerem o que pensam ou têm a pintar. Não há nenhuma restrição. 
A nossa democracia é muito "balbuciante". Há muitos problemas e é preciso que as pessoas entendam que se vive numa sociedade democrática. De maneira nenhuma me parece que haja alguma restrição na proclamação criadora dos artistas. Ninguém impede que o artista possa criar o que lhe apetece.

\section{Que mensagem e conselho quer deixar aos novos artistas?}

Infelizmente, este grupo de jovens artistas que está aparecendo não tem tido muito apoio. E quando digo que não tem tido apoio refiro-me a quem toma decisões, pois não olha com atenção para o fenômeno artístico em Angola. E quem sofre principalmente com o ostracismo são, sem dúvida, as novas gerações. Há pessoas com muitas qualidades, que têm uma produção bastante interessante, e que precisam de ser mais acarinhadas. Elas têm

que tentar virar-se por si próprias. É um pouco o que fizemos também. As pessoas da minha geração nunca encontraram grande eco nas suas preocupações. Parece-me que vai levar algum tempo.

Quando digo "acarinhar" é o mesmo que dizer: é preciso criar situações para que estes artistas criem em melhores condições e estejam mais informados acerca do que se passa a nível do continente e fora. 